\title{
Recent Advances in Treatment of Primary Central Nervous System Lymphoma
}

\author{
Lakshmi Nayak, MD ${ }^{1}$ \\ Tracy T. Batchelor, MD MPH ${ }^{2 *}$
}

\author{
Address \\ ${ }^{1}$ Dana-Farber Cancer Institute, Center for Neuro-Oncology, Department \\ of Neurology, Brigham and Women's Hospital, Harvard Medical School, \\ 450 Brookline Avenue, Boston, MA 02215, USA \\ 2, ${ }^{*}$ Stephen E. and Catherine Pappas Center for Neuro-Oncology, Division of Hematology \\ and Oncology, Department of Neurology, Massachusetts General Hospital Cancer Center, \\ Harvard Medical School, 55 Fruit Street, Boston, MA 02114, USA \\ Email: tbatchelor@partners.org
}

Published online: 11 August 2013

(C) The Author(s) 2013. This article is published with open access at Springerlink.com

Keywords Primary central nervous system lymphoma - High-dose methotrexate - Rituximab - Stem-cell transplant . Whole-brain radiation

\section{Opinion statement}

Therapeutic options are limited in primary central nervous system lymphoma (PCNSL) with no uniform consensus on optimal management and few published, randomized trials. High-dose methotrexate in combination with other chemotherapeutic agents forms the mainstay of treatment. There hasn't been much progress beyond high-dose methotrexate in this disease, and although results from trials using high-dose chemotherapy and autologous stem-cell transplant seem promising, these need to be further validated. Moreover, the role of whole brain radiation in the upfront setting remains to be determined. However, international efforts in this direction are underway, with ongoing randomized trials in newly diagnosed PCNSL, more research on the molecular pathogenesis and biomarkers, and the use of novel agents in salvage therapy. There also is emphasis on quality of life parameters and neurocognitive status. Future treatment options should optimize high-efficacy rates while minimizing the risk of neurotoxicity.

\section{Introduction}

Primary central nervous system lymphoma (PCNSL) is an extranodal non-Hodgkin lymphoma (NHL) arising from the brain, spinal cord, eyes or leptomeninges, in the absence of prior or concurrent systemic disease. More than $90 \%$ of PCNSL are diffuse large B-cell lym- phomas and are sensitive to chemotherapy and radiation. But relapse rates are high with poor long-term survival compared with other forms of NHL. A minority of the patients does achieve long-term remission ( $>5$ years) with a potential hope for cure, although late 
relapses have been noted. Moreover, long-term survivors are at a risk of delayed neurotoxicity.

\section{Epidemiology}

PCNSL accounts for $2.2 \%$ of all primary central nervous system tumors, with a median age of 65 years at diagnosis [1]. The annual incidence rate is 0.47 cases per 100,000 person-years [1, 2]. Since 2000, there has been a slight increase in overall incidence, with a dramatic increase in incidence in the elderly, particularly those $>75$ years of age at diagnosis.

\section{Diagnosis}

The diagnosis of PCNSL can be made by stereotactic brain biopsy, cerebrospinal fluid (CSF) cytopathologic analysis, or by analysis of vitreous aspirate in patients with ocular involvement. The International PCNSL Col- laborative Group (IPCG) recommends evaluation for the extent of disease before initiation of therapy [3].

\section{Prognostic factors}

Age and performance status have been consistently identified to be independently associated with prognosis. Two scoring systems (the International Extranodal Lymphoma Study Group (IELSG) scoring system and the Memorial Sloan-Kettering Cancer Center prognostic model) currently exist that help serve as guidelines to determine prognosis and treatment options in newly diagnosed patients, as well as to stratify patients to facilitate comparison across clinical trials $[4,5]$. In terms of biomarkers, overexpression of BCL6 has been shown to be associated with better prognosis in most studies except a recent study, which indicated that high BCL6 expression correlated with poor survival $[6,7,8 \bullet]$.

\section{Treatment}

The treatment of PCNSL involves use of high-dose methotrexate (HD-MTX) in varying doses $\left(1-8 \mathrm{~g} / \mathrm{m}^{2}\right)$, used as a single agent or in combination with other chemotherapeutic agents and/or radiotherapy. There is no consensus on the dose of HD-MTX or the optimal combination of chemotherapy, neither is there consensus on the role of radiation in combination with methotrexate as first-line therapy. There is no role of surgical resection in treatment of this disease [9].

Historically, PCNSL was treated with whole brain radiation (WBRT), which resulted in high rates of radiographic response but also rapid relapse. WBRT alone is no longer employed for initial treatment. Also, PCNSL is thought to be an infiltrating disease and focal RT is not recommended. A multicenter, phase II trial was conducted in the 1980s in which 41 patients treated with WBRT to 40 Gy plus a 20 Gy boost to the tumor achieved a median overall survival (OS) of 12 months, with majority of the recurrences occurring in the region of the boost [10]. Shibamoto and colleagues reported a median survival of 18 months in a retrospective analysis of 132 patients treated in the 1990s with WBRT monotherapy at different doses [11]. Later studies demonstrated that high doses of methotrexate could achieve therapeutic concentrations in the brain, and when combined with WBRT led to sustained response [12-15]. Most of these studies used high doses of WBRT up to 45 Gy and some included focal boost. However, there was a high incidence 
of neurotoxicity with this combined modality treatment [16]. This led to studies utilizing lower doses of WBRT. A post-hoc analysis of two phase II trials utilizing the same induction chemotherapy, but different doses of WBRT suggested that lowering the dose of consolidation WBRT from 45 to 30.6 Gy led to poor outcomes in patients younger than age 60 years [14]. However, other studies have demonstrated conflicting results. A prospective study showed no neurocognitive decline after consolidation reduced-dose WBRT (23.4 Gy) and cytarabine in patients who had achieved a complete response to induction chemotherapy including HD-MTX [17]. Furthermore, there was no significant cognitive decline up to 24 months after treatment as demonstrated by prospective, neuropsychological testing and six of eight patients were able to return to work [18]. More recently, a retrospective analysis of varying fields and doses of RT in 33 patients who had achieved a complete response to HD-MTX containing regimen indicated that higher WBRT and tumor bed RT doses (>40 Gy) do not improve outcome and are associated with a greater risk of neurotoxicity [19•]. But, delayed neurotoxicity from combined modality treatment especially with advancing age and prolonged progression-free survival (PFS) is well-recognized [20]. Recently, Correa and colleagues identified 50 PCNSL survivors in remission and found that those that were treated with HD-MTX and conventional doses of WBRT had significant neurocognitive dysfunction that interfered with quality of life and $>50 \%$ of these patients were not working due to their illness. On the contrary, patients that received HD-MTX alone did not have significant cognitive impairment and had preserved quality of life [21 $\bullet$.

There has been considerable debate whether adding WBRT to methotrexate-based chemotherapy adds to any benefit in terms of PFS or OS. Omuro et al. sought to examine the effects of deferring WBRT. Sixty-four patients younger than age 60 years were treated with a combination of HD-MTX ( $3 \mathrm{~g} /$ $\mathrm{m}^{2}$ ), lomustine, procarbazine, methylprednisolone, and intrathecal methotrexate, cytarabine, and methylprednisolone, of whom $54 \%$ had a complete response and did not receive any further treatment [22]. All other patients underwent WBRT, high-dose chemotherapy followed by autologous stem cell transplant, or maintenance chemotherapy. They found that deferring WBRT affected PFS but not OS. Because salvage WBRT was required, neurotoxicity was delayed but not eliminated. Another retrospective study of 122 patients showed no OS benefit in patients who received consolidation treatment with WBRT compared with those who did not, but higher rates of neurotoxicity were seen in those who received WBRT [23]. Other retrospective studies had similar findings [24, 25].

The German PCNSL study group conducted a phase III trial where patients were randomized to receive HD-MTX-based chemotherapy with or without WBRT [26••]. A total of 551 patients were enrolled of whom 318 were treated per protocol. The authors reported a median OS of 32.4 months (95\% confidence interval (CI), 25.8-39) in the cohort receiving WBRT versus 37.1 months $(95 \% \mathrm{CI}, 27.5-46.7)$ in the cohort that did not receive WBRT as a part of first-line treatment, with a hazard ratio of 1.06 (95\% CI, 0.8-1.4) and $p$ value of 0.71 . Although the OS was not statistically different in both groups, the primary hypothesis of non-inferiority of HD-MTX-based regimen over the same chemotherapy followed by WBRT was not proven due to an underpowered study (60\% power) and noninferiority margin of 0.9 . Serial 
neurocognitive testing was not performed, so definitive assessment of neurotoxicity was not possible.

High-dose methotrexate forms the backbone of induction chemotherapy for PCNSL. It is able to achieve cytotoxic levels in the brain parenchyma and CSF $[27,28]$. Various studies have used different doses and schedules of HDMTX, but in general, dose $\geq 3 \mathrm{~g} / \mathrm{m}^{2}$ delivered as an initial bolus followed by an infusion over 3 hours, administered every 10 to 21 days is recommended for favorable outcomes and adequate CSF concentrations [25, 29, 30].

There have been various studies using HD-MTX alone or in combination with other cytotoxic agents and/or WBRT. Concern for WBRT-induced neurotoxicity has led to chemotherapy alone trials.

A multicenter, phase II study of single-agent HD-MTX at $8 \mathrm{~g} / \mathrm{m}^{2}$ given every 14 days as induction therapy followed by monthly maintenance cycles for 12 months in 25 patients yielded an complete response rate (CRR) of $52 \%$ and an overall response rate (ORR) of $74 \%$ with a median PFS of 12.8 months and a median OS of 55.4 months $[31,32]$. In another multicenter trial of 37 patients treated with a maximum of six induction cycles of HD-MTX at $8 \mathrm{~g} / \mathrm{m}^{2}$, the results were not as compelling. The CRR was $30 \%$, median PFS was 10 months, and the median OS was lower than the other study at 25 months [33]. Studies have demonstrated higher complete response proportions in patients who receive more than six induction cycles of methotrexate-based chemotherapy [17, 31].

In general, combination chemotherapy is thought to achieve higher response rates with longer durability. A pilot and phase II study of 65 patients was conducted using HD-MTX at $5 \mathrm{~g} / \mathrm{m}^{2}$ and cytarabine in combination with dexamethasone, vincristine, vindesine, ifosfamide, cyclophosphamide, and intraventricular methotrexate, cytarabine, and prednisolone [34]. The investigators reported a CRR of $61 \%$, median PFS of 21 months and median OS of 50 months. At a median follow up of 100 months, $32 \%$ of all patients and $57 \%$ of patients $\leq 60$ years of age were still alive [35]. However, there was a fair amount of toxicity associated with this regimen; $9 \%$ of patients died and $19 \%$ developed infections of the Ommaya reservoir. Interestingly, serial neuropsychologic testing demonstrated no evidence of cognitive decline in the majority of the patients. Due to the high rate of Ommaya reservoir infections in the prior trial, the same group conducted another phase II trial with the same systemic regimen without the intraventricular treatment in 18 patients [36]. The CRR was $53 \%$, the median duration of response was only 10 months, and median PFS was 8 months in all patients, as a result of which the trial was terminated early. The results of this study seem to support a role intraventricular chemotherapy. However, a retrospective study demonstrated no benefit in OS, PFS or neurotoxicity of adding intrathecal methotrexate to a HD-MTX-based regimen [37]. Similar results were found in another retrospective analysis of 69 PCNSL patients with no evidence of positive or suspicious CSF cytology, of whom 39 received HD-MTX-based chemotherapy $\left(1-3 \mathrm{~g} / \mathrm{m}^{2}\right.$ depending on age) and intrathecal methotrexate, cytarabine, and methylprednisolone, and the other 30 received the same systemic chemotherapy with omission of intrathecal treatment [38•]. The authors found no significant difference in response rates, 
patterns of relapse, and OS regardless of intrathecal treatment. The median PFS was 28.7 months (95\% CI, 11.1-40.1) in the group receiving intrathecal prophylaxis versus 9.9 months ( $95 \% \mathrm{CI}, 5.6-27.4)$ in the other group, with a $p$ value of 0.0518 .

Ferreri and colleagues reported the results from the first successfully completed randomized, phase II trial in PCNSL where 79 patients were treated with single-agent HD-MTX ( $3.5 \mathrm{~g} / \mathrm{m}^{2}$ every 21 days) versus HD-MTX and cytarabine [15]. All patients underwent WBRT after induction chemotherapy. The authors reported improved efficacy and activity with the addition of cytarabine to methotrexate and demonstrated that combination chemotherapy is better than methotrexate monotherapy at this dose and schedule. CRR was $46 \%$ in the cytarabine plus methotrexate arm versus $18 \%$ in methotrexate monotherapy arm, and 3-year OS was $46 \%$ and $32 \%$, respectively.

Intra-arterial delivery of methotrexate in conjunction with blood-brain barrier disruption has been studied and reported in a series of 149 patients from multiple institutions [39]. The authors reported an ORR and CRR of $82 \%$ and $58 \%$, respectively, with a median PFS and OS of 1.8 and 3.1 years, respectively. Toxicities unique to this method of delivery included peri-procedural seizures in $33.6 \%$, carotid or vertebral artery injury in $10.7 \%$, and strokes in $7.4 \%$ of the patients.

More recently, rituximab, a chimeric monoclonal antibody targeting CD20 antigen on B-lymphocytes, is being incorporated in combination regimens. When administered in doses of $375-800 \mathrm{mg} / \mathrm{m}^{2}$, CSF levels from $0.1 \%$ to $4.4 \%$ of serum levels have been noted on pharmacokinetic studies [17, 40].

Shah et al. demonstrated a CRR of $78 \%$ after 7 cycles of HD-MTX at $3.5 \mathrm{~g} /$ $\mathrm{m}^{2}$ in combination with rituximab, procarbazine, and vincristine [17]. All patients underwent WBRT (23.4 vs. 45 Gy depending on response to induction) followed by cytarabine. The estimated 2-year PFS and OS was $57 \%$ and $67 \%$ after a median follow-up of 37 months.

Rubenstein and colleagues studied the effects of a 2-step dose-intensive immunochemotherapeutic regimen in a multicenter cooperative group setting [8•]. In this trial, 44 patients were treated with induction chemotherapy consisting of HD-MTX at $8 \mathrm{~g} / \mathrm{m}^{2}$ (day 1), rituximab at $375 \mathrm{mg} / \mathrm{m}^{2}$ (day 3), and temozolomide at $150 \mathrm{mg} / \mathrm{m}^{2}$ (days 7-11). Each of the drugs in the MTR induction regimen has been studied as single agents with demonstrated activity in PCNSL. MTR induction was followed by consolidation chemotherapy that included intravenous etoposide $5 \mathrm{mg} / \mathrm{kg}$ as a continuous infusion over 96 hours (total $40 \mathrm{mg} / \mathrm{kg}$ ) and cytarabine at $2 \mathrm{~g} / \mathrm{m}^{2}$ every 12 hours for 8 doses. The CRR on induction chemotherapy was $66 \%$. With a median follow-up of 4.9 years, the 2-year PFS was $57 \%$, the median PFS was 4 years, and the median OS was not reached. Major toxicity was grade 4 neutropenia and thrombocytopenia seen in approximately $50 \%$ of the patients, and the majority of these episodes were after consolidation chemotherapy. There was one treatment-related death. These results are encouraging and are comparable to any regimen that includes WBRT. Moreover, in this study median PFS was similar for older ( $>60$ years of age) and younger patients. This is an interesting finding as prior studies have shown that patients older than 60 years of age have worse outcomes [5]. The authors also reported shorter PFS in patients that delayed induction chemotherapy beyond 1 month of diagnosis compared to those that did not (3-year PFS of $20 \%$ vs. $59 \%, p=0.05)$. 


\section{High-dose chemotherapy and stem cell transplantation}

Chemotherapy and radiation have high efficacy rates in PCNSL, but responses are not durable. Moreover, there is always the issue of neurotoxicity from radiation. There has been emerging data on the role of high-dose chemotherapy (HDCT) followed by autologous stem cell transplantation (ASCT) as first-line therapy for consolidation in PCNSL. Abrey et al. treated 28 patients with HD-MTX and cytarabine for induction followed by treatment with carmustine, etoposide, cytarabine, melphalan (BEAM), and ASCT [41]. The results were disappointing with a median PFS of 5.6 months for all patients and 9.3 months for those who underwent ASCT. Subsequently, a multicenter, phase II trial was conducted in which 25 patients $<60$ years of age received induction chemotherapy with HD-MTX, etoposide, carmustine, and methylprednisolone, then ifosfamide and cytarabine, followed by BEAM and ASCT, after which patients received WBRT [42]. This study demonstrated better results with a median PFS of 40 months. More recently, conditioning regimens have included thiotepa and results have been more encouraging, likely due to better CNS penetration. In a phase II trial, 23 patients were treated with HD-MTX followed by high-dose thiotepa/busulfan and ASCT, and response-adapted WBRT. The median PFS was 17 months [43]. On longterm follow-up 10 years after initiation of study, the OS rate was $35 \%$; six patients remained in complete remission, and the majority of the patients who did not receive WBRT had no evidence of neurotoxicity [44•]. Illerhaus and colleagues treated 43 patients with one of two HD-MTX-based induction regimens followed by high-dose carmustine/thiotepa and ASCT with/ without WBRT in two prospective trials $[45,46]$. They reported a 5-year OS of $70 \%$ and 5-year PFS of $67 \%$ [47]. In a single-center study of 11 patients treated with HD-MTX and cytarabine, followed by busulfan, cyclophosphamide, etoposide, and ASCT, the median PFS was 15 months [48]. Recently, Illerhaus et al. reported the results of a multicenter study in which 79 patients were treated with induction HD-MTX, cytarabine, rituximab and thiotepa, followed by carmustine/thiotepa conditioning before ASCT, with an ORR of $91 \%$ and 2-year OS $87 \%$ [49•]. Five patients died from the treatment. A retrospective analysis of 105 patients treated with HDCT followed by ASCT with/without WBRT demonstrated 5-year OS of $79 \%$ and median PFS and OS of 85 and 121 months, respectively [50•]. Based on the results of these phase II trials, this mode of consolidative treatment seems very promising. The toxicities, mostly cytopenias, are manageable. There are two ongoing, multicenter, randomized trials comparing the efficacy of consolidative HDCT and ASCT versus chemotherapy or WBRT (Table 1).

\section{Treatment in the elderly}

The elderly account for more than half of the patients with PCNSL [51]. The risk of neurotoxicity is the highest in this population, and in general, chemotherapy alone is a reasonable option. In a study using a HD-MTX-based regimen and WBRT, almost $90 \%$ of patients $>60$ years of age developed delayed neurotoxicity and died from related complications, rather than recurrent disease [52]. On the other hand, almost $50 \%$ of older patients who deferred WBRT died of progressive disease. Thus, deferring WBRT in older patients reduced treatmentrelated neurotoxicity and did not compromise OS. Various studies have indi- 


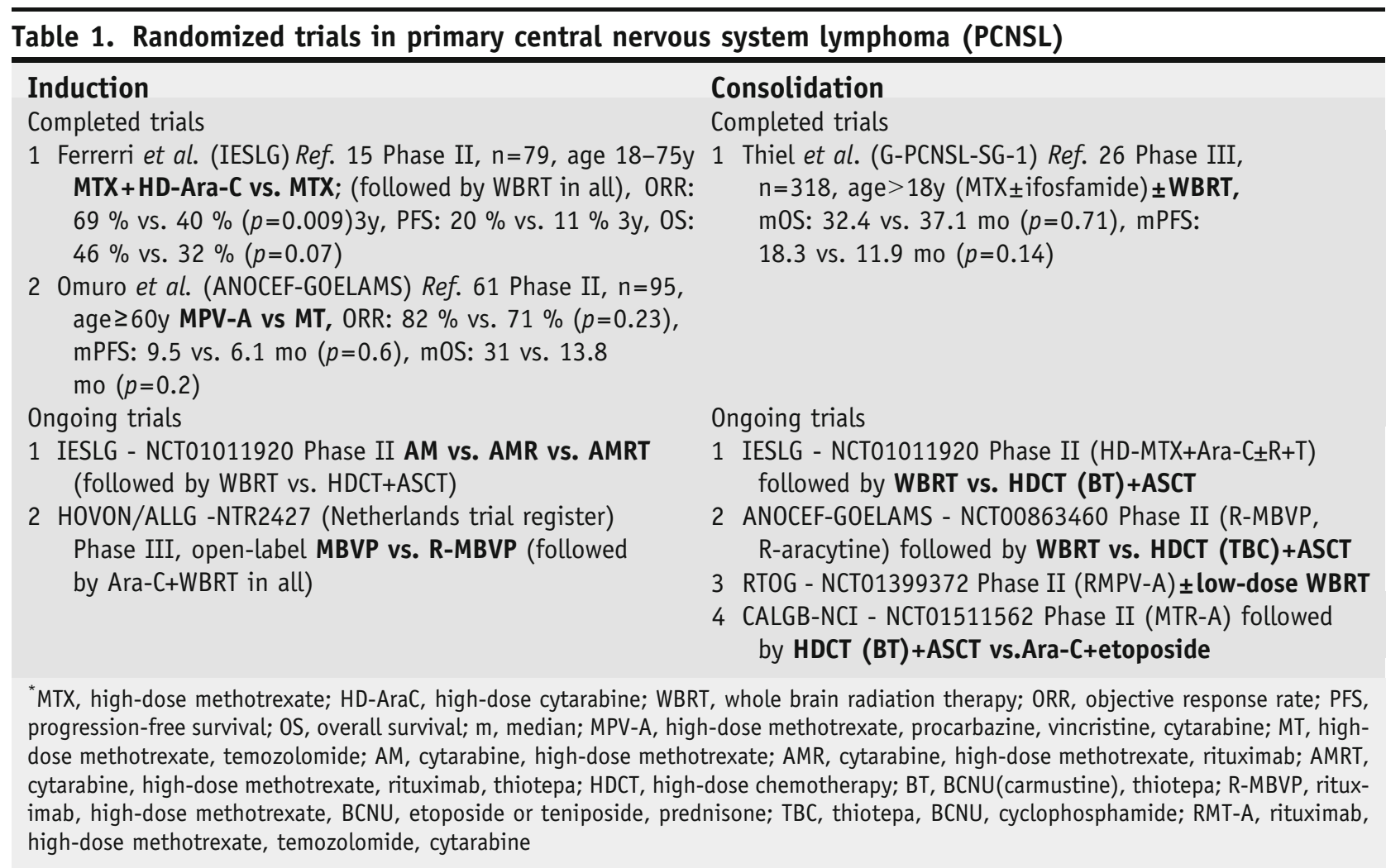

cated that HD-MTX at doses of $3.5-8 \mathrm{~g} / \mathrm{m}^{2}$ is well tolerated in these patients with minimal grade 3 or 4 renal and hematological toxicity [53-55]. Zhu and colleagues reported a series of 31 patients $\geq 70$ years of age who were treated with a median of eight cycles of single-agent HD-MTX at 3.5-8 $\mathrm{g} / \mathrm{m}^{2}$ and demonstrated an ORR of $96.7 \%$ with a CRR of $60 \%$ [54]. The median PFS was 7.1 months and median OS was 37 months. In a retrospective study of 24 patients $\geq 80$ years of age, 23 were treated with HD-MTX-based regimen without significant renal toxicity despite low creatinine clearance at baseline and were found to have a 2-year OS of $33 \%$ [56].

Combination chemotherapy has been tried successfully in older patients and found to be relatively well-tolerated. A phase II trial was conducted in 23 patients $>60$ years of age who received HD-MTX at $3 \mathrm{~g} / \mathrm{m}^{2}$ (days 1, 10, 20) and temozolomide at $100 \mathrm{mg} / \mathrm{m}^{2}$ (days 1-5) followed by up to 5 maintenance monthly cycles of HD-MTX and temozolomide in responders [57]. A CR was seen in $55 \%$ of the patients, and median PFS and OS were 8 and 35 months, respectively. A multicenter phase II trial of up to six cycles of HD$\operatorname{MTX}\left(5 \mathrm{~g} / \mathrm{m}^{2}\right)$, lomustine, vincristine, methylprednisolone, and intrathecal methotrexate and cytarabine in 50 patients with median age of 72 years (>60 years) resulted in a CRR of $42 \%$, with median PFS and OS of 10.6 and 14.3 months [58]. Illerhaus and colleagues evaluated the effects of three 45day cycles of HD-MTX at $3 \mathrm{~g} / \mathrm{m}^{2}$ (days 1, 15, 30) with procarbazine at $60 \mathrm{mg} /$ $\mathrm{m}^{2}$ (days $1-10$ ) and lomustine at $110 \mathrm{mg} / \mathrm{m}^{2}$ (day1) in a phase II trial with 30 patients $\geq 65$ years of age [59]. CRR was $44.4 \%$, and median PFS and OS were 
5.9 and 15.4 months, respectively. Subsequently, the same group conducted another trial with the addition of rituximab to the same regimen [60]. In 28 patients, the CRR was $64 \%$, with a median PFS and OS of 16 and 17.5 months respectively, and 3-year PFS and OS rate of $31 \%$. Median OS was remarkably better in patients $<80$ years of age at 29 months, and 4.3 months in those older. There were two treatment-related deaths. The ANOCEF-GOELAMS study was a multicenter, randomized, phase II trial of chemotherapy alone in elderly patients with PCNSL [61 $\bullet$. In this study, 98 patients were randomized to receive three cycles of either MPV-A (methotrexate $3.5 \mathrm{~g} / \mathrm{m}^{2}$, days 1 and 15; procarbazine $100 \mathrm{mg} / \mathrm{m}^{2}$, days $1-7$; vincristine $1.4 \mathrm{mg} / \mathrm{m}^{2}$, days 1 and 15 ) or MT (methotrexate $3.5 \mathrm{~g} / \mathrm{m}^{2}$, days 1 and 15 ; temozolomide $100-150 \mathrm{mg} / \mathrm{m}^{2}$, days $1-5,15-19)$ with one additional cycle of cytarabine $\left(3 \mathrm{~g} / \mathrm{m}^{2} /\right.$ day for 2 consecutive days) in the MPV arm only. While there were trends favoring the MPV-A regimen over the MT regimen with respect to complete response rate, PFS and OS, none of these differences reached statistical difference. Recently published data suggest that the addition of rituximab to both MPV and MT increased the radiographic response rate. Both of these chemotherapy regimens are options in elderly PCNSL patients.

Despite high response rates seen with initial HD-MTX based treatments, many patients with PCNSL relapse. Moreover, there is a small subset of patients that have methotrexate-refractory disease. Prognosis of progressive or relapsed PCNSL is poor with a limited number of prospective studies for guidance on management. Rechallenge with HD-MTX has been shown to be effective in patients that had previously responded to it. In a multicenter retrospective review of 22 patients, $91 \%$ had a radiographic response to first salvage treatment with HD-MTX and $100 \%$ to second salvage [62]. The median OS from first salvage was 61.9 months.

Pemetrexed, which is similar to methotrexate with antifolate activity, has been shown to been efficacious in recurrent or refractory PCNSL. In a trial of 11 patients who were treated with a median of 5 cycles of pemetrexed at $900 \mathrm{mg} / \mathrm{m}^{2}$ administered every 3 weeks, there was a ORR of $55 \%$ with 6month PFS of $45 \%$ [63•].

Rituximab and temozolomide have been studied in combination as well as single agents in relapsed PCNSL. A retrospective review of 17 patients with single-agent temozolomide demonstrated a median OS of 6.7 months [64]. A prospective study of 36 patients treated with temozolomide reported a ORR and 1-year OS of $31 \%$ [65]. In a multicenter pilot study of single agent rituximab in 12 patients, the ORR was $31 \%$ with a median OS of 20.9 months [66・]. While prior retrospective studies of combination rituximab and temozolomide demonstrated promising results of ORR of 53$100 \%$ and 1-year OS of $55 \%$, a multicenter phase II trial failed to reproduce the results with early closure of the trial for a poor response rate of $14 \%$ and median PFS of 7 weeks [67-69]. However, this may have been due to patient selection bias. Given this regimen is very well tolerated, it is recommended in a selected population of patients.

Topotecan also has been found to be useful in salvage treatment with response rates of $33-40 \%$ and median OS of 8.4 and 35 months in two differ- 
ent studies [70, 71]. Other salvage treatments have included combination of etoposide, ifosfamide, and cytarabine, and procarbazine, lomustine, and vincristine with response rates of $37 \%$ and $86 \%$, respectively, and 1-year OS of $41 \%$ and $57 \%$, respectively $[72,73]$. Rubenstein and Treseler successfully treated a patient with intraocular lymphoma with lenalidomide, an immunomodulating drug (IMiD) [74].

Intraventricular rituximab has been studied by itself and in combination with intraventricular methotrexate in phase I trials $[75,76]$. Fourteen patients were treated with intraventricular rituximab and methotrexate, of whom $43 \%$ had a CR in CSF and/or brain [76].

The most impressive results are from a phase II trial conducted by Soussain and colleagues in 43 patients who were treated with initial high-dose cytarabine and etoposide followed by HDCT with thiotepa, busulfan, cyclophosphamide, and ASCT [77]. In this study, 27 patients underwent transplantation, of whom 26 had a CR. The median PFS and OS in these 27 patients were 41.1 and 58.6 months, respectively. Kasenda et al. demonstrated that a second autotransplantation is successful as salvage treatment in patients who have previously undergone HDCT and ASCT [78].

Allogeneic peripheral blood stem cell transplantation (allo PBSCT) has been found to be successful in patients with leukemia/lymphoma with CNS involvement [79-82]. There is one case report in the literature in which the authors reported a patient with PCSNL who was in complete remission 3 months after the transplantation and remained so for 30 months [83].

Finally, WBRT in patients who have not received it as a part of initial treatment is an effective option, although there is certainly a risk of neurotoxicity. Many clinicians reserve this for those with chemotherapy-refractory disease in whom the disease has progressed through chemotherapy at initial treatment or at relapse. In a series of 27 patients treated with WBRT (median dose $36 \mathrm{~Gy}$ ), $74 \%$ achieved a radiographic response and median OS was 10.6 months [84]. Late neurotoxicity rates of $15 \%$ were noted at doses $>36$ Gy. Another study in 48 patients treated with a median dose of $40 \mathrm{~Gy}$, reported an ORR of $79 \%$ with a median OS of 16 months and treatment-related neurotoxicity in $22 \%$ of patients [85].

Although randomized clinical trials have been lacking in the field of PCNSL, there are now several clinical trials through cooperative groups investigating various questions regarding optimal treatment strategies (Table 1). These studies are designed to examine the optimal induction regimen, the role of rituximab in induction, the benefit of consolidative reduced-dose radiation, as well as comparing high-dose chemotherapy to myeloablative chemotherapy for consolidation. There are currently two trials in progress that are comparing consolidative WBRT versus HDCT and ASCT, both utilizing different conditioning regimens prior to ASCT. Some of these studies also include correlative biomarkers and imaging components as well as assessment of neurocognitive and quality of life outcomes assessment.

In terms of salvage therapy, novel agents are currently being tested after their success in systemic B-cell lymphoma. Currently, there are ongoing trials 
utilizing the combination of lenalidomide and rituximab (NCT01542918), single-agent pomalidomide (NCT01722305), and single-agent temsirolimus (NCT00942747) in treatment of relapsed PCNSL.

\section{Conflict of Interest}

Lakshmi Nayak declares no conflict of interest.

Tracy T. Batchelor is a consultant to Merck \& Co., Inc, Roche, Kirin Pharmaceuticals, Spectrum, Amgen, and Novartis.

\section{Human and Animal Rights and Informed Consent}

This article does not contain any studies with human or animal subjects performed by any of the authors.

\section{Open Access}

This article is distributed under the terms of the Creative Commons Attribution License which permits any use, distribution, and reproduction in any medium, provided the original author(s) and the source are credited.

\section{References and Recommended Reading}

Papers of particular interest, published recently, have been highlighted as:

- Of importance,

$\bullet$ Of major importance

1. Dolecek TA, Propp JM, Stroup NE, Kruchko C. CBTRUS statistical report: primary brain and central nervous system tumors diagnosed in the United States in 2005-2009. Neuro Oncol. 2012;14 Suppl 5:v1-49.

2. Villano JL, Koshy M, Shaikh H, et al. Age, gender, and racial differences in incidence and survival in primary CNS lymphoma. Br J Cancer. 2011;105:1414-8.

3. Abrey LE, Batchelor TT, Ferreri AJ, et al. Report of an international workshop to standardize baseline evaluation and response criteria for primary CNS lymphoma. J Clin Oncol. 2005;23:5034-43.

4. Ferreri AJ, Blay JY, Reni M, et al. Prognostic scoring system for primary CNS lymphomas: the international extranodal lymphoma study group experience. J Clin Oncol. 2003;21:266-72.

5. Abrey LE, Ben-Porat L, Panageas KS, et al. Primary central nervous system lymphoma: the Memorial Sloan-Kettering Cancer Center prognostic model. J Clin Oncol. 2006;24:5711-5.

6. Braaten KM, Betensky RA, de Leval L, et al. BCL-6 expression predicts improved survival in patients with primary central nervous system lymphoma. Clin Cancer Res. 2003;9:1063-9.

7. Levy O, Deangelis LM, Filippa DA, et al. Bcl-6 predicts improved prognosis in primary central nervous system lymphoma. Cancer. 2008;112:151-6.

8. Rubenstein JL, Hsi ED, Johnson JL, et al.: Intensive Chemotherapy and Immunotherapy in Patients With Newly Diagnosed Primary CNS Lymphoma: CALGB 50202 (Alliance 50202). J Clin Oncol, 2013 (Epub). In this prospective study, the authors demonstrated excellent outcomes with HD-MTX based regimen followed by intensive chemotherapy for consolidation. Based on these results, CALGB is now conducting a trial comparing this regimen with high-dose chemotherapy and autologous stem-cell rescue.

9. Bellinzona M, Roser F, Ostertag H, et al. Surgical removal of primary central nervous system lymphomas (PCNSL) presenting as space occupying lesions: a series of 33 cases. Eur J Surg Oncol. 2005;31:100-5.

10. Nelson DF, Martz KL, Bonner H, et al. NonHodgkin's lymphoma of the brain: can high dose, large volume radiation therapy improve survival? Report on a prospective trial by the Radiation Ther- 
apy Oncology Group (RTOG): RTOG 8315. Int J Radiat Oncol Biol Phys. 1992;23:9-17.

11. Shibamoto Y, Ogino H, Hasegawa M, et al. Results of radiation monotherapy for primary central nervous system lymphoma in the 1990s. Int J Radiat Oncol Biol Phys. 2005;62:809-13.

12. DeAngelis LM, Seiferheld W, Schold SC, et al. Combination chemotherapy and radiotherapy for primary central nervous system lymphoma: radiation therapy oncology group study 93-10. J Clin Oncol. 2002;20:4643-8.

13. Poortmans PM, Kluin-Nelemans HC, Haaxma-Reiche $\mathrm{H}$, et al. High-dose methotrexate-based chemotherapy followed by consolidating radiotherapy in nonAIDS-related primary central nervous system lymphoma: European organization for research and treatment of cancer lymphoma group phase II Trial 20962. J Clin Oncol. 2003;21:4483-8.

14. Bessell EM, Lopez-Guillermo A, Villa S, et al. Importance of radiotherapy in the outcome of patients with primary CNS lymphoma: an analysis of the CHOD/ BVAM regimen followed by two different radiotherapy treatments. J Clin Oncol. 2002;20:231-6.

15. Ferreri AJ, Reni M, Foppoli M, et al. High-dose cytarabine plus high-dose methotrexate versus highdose methotrexate alone in patients with primary CNS lymphoma: a randomised phase 2 trial. Lancet. 2009;374:1512-20.

16. Correa DD, Maron L, Harder $\mathrm{H}$, et al. Cognitive functions in primary central nervous system lymphoma: literature review and assessment guidelines. Ann Oncol. 2007;18:1145-51.

17. Shah GD, Yahalom J, Correa DD, et al. Combined immunochemotherapy with reduced whole-brain radiotherapy for newly diagnosed primary CNS lymphoma. J Clin Oncol. 2007;25:4730-5.

18. Correa DD, Rocco-Donovan M, DeAngelis LM, et al. Prospective cognitive follow-up in primary CNS lymphoma patients treated with chemotherapy and reduceddose radiotherapy. J Neurooncol. 2009;91:315-21.

19. Ferreri AJ, Verona C, Politi LS, et al. Consolidation radiotherapy in primary central nervous system lymphomas: impact on outcome of different fields and doses in patients in complete remission after upfront chemotherapy. Int J Radiat Oncol Biol Phys. 2011;80:169-75.

In this retrospective study, the authors showed that patient outcomes did not vary irrespective of the dose and field of RT.

20. Omuro AM, Ben-Porat LS, Panageas KS, et al. Delayed neurotoxicity in primary central nervous system lymphoma. Arch Neurol. 2005;62:1595-600.

21. Correa DD, Shi W, Abrey LE, et al. Cognitive functions in primary CNS lymphoma after single or combined modality regimens. Neuro Oncol. 2012;14:101-8.

This was a retrospective comparison of neurocognitive status in patients treated with HD-MTX with/without WBRT with respect to neuropsychologic evaluation, quality of life and MRI changes.

22. Omuro A, Taillandier L, Chinot O, et al. Primary CNS lymphoma in patients younger than 60: can wholebrain radiotherapy be deferred? J Neurooncol. 2011;104:323-30.

23. Ekenel M, Iwamoto FM, Ben-Porat LS, et al. Primary central nervous system lymphoma: the role of consolidation treatment after a complete response to high-dose methotrexate-based chemotherapy. Cancer. 2008;113:1025-31.

24. Ferreri AJ, Reni M, Pasini F, et al. A multicenter study of treatment of primary CNS lymphoma. Neurology. 2002;58:1513-20.

25. Reni M, Ferreri AJ, Guha-Thakurta N, et al. Clinical relevance of consolidation radiotherapy and other main therapeutic issues in primary central nervous system lymphomas treated with upfront high-dose methotrexate. Int J Radiat Oncol Biol Phys. 2001;51:419-25.

26.• Thiel E, Korfel A, Martus P, et al. High-dose methotrexate with or without whole brain radiotherapy for primary CNS lymphoma (G-PCNSL-SG-1): a phase 3, randomised, non-inferiority trial. Lancet Oncol. 2010;11:1036-47.

This is the first completed randomized phase III trial in PCNSL. This study assessed the role of WBRT for consolidation in patients treated with HD-MTX based regimen.

27. Blakeley JO, Olson J, Grossman SA, et al. Effect of blood brain barrier permeability in recurrent high grade gliomas on the intratumoral pharmacokinetics of methotrexate: a microdialysis study. J Neurooncol. 2009;91:51-8.

28. Glantz MJ, Cole BF, Recht L, et al. High-dose intravenous methotrexate for patients with nonleukemic leptomeningeal cancer: is intrathecal chemotherapy necessary? J Clin Oncol. 1998;16:1561-7.

29. Ferreri AJ, Guerra E, Regazzi M, et al. Area under the curve of methotrexate and creatinine clearance are outcome-determining factors in primary CNS lymphomas. Br J Cancer. 2004;90:353-8.

30. Hiraga S, Arita N, Ohnishi T, et al. Rapid infusion of high-dose methotrexate resulting in enhanced penetration into cerebrospinal fluid and intensified tumor response in primary central nervous system lymphomas. J Neurosurg. 1999;91:221-30.

31. Batchelor T, Carson K, O'Neill A, et al. Treatment of primary CNS lymphoma with methotrexate and deferred radiotherapy: a report of NABTT 96-07. J Clin Oncol. 2003;21:1044-9.

32. Gerstner ER, Carson KA, Grossman SA, Batchelor TT. Long-term outcome in PCNSL patients treated with high-dose methotrexate and deferred radiation. Neurology. 2008;70:401-2.

33. Herrlinger $\mathrm{U}$, Kuker W, Uhl M, et al. NOA-03 trial of high-dose methotrexate in primary central nervous system lymphoma: final report. Ann Neurol. 2005;57:843-7. 
34. Pels H, Schmidt-Wolf IG, Glasmacher A, et al. Primary central nervous system lymphoma: results of a pilot and phase II study of systemic and intraventricular chemotherapy with deferred radiotherapy. J Clin Oncol. 2003;21:4489-95.

35. Juergens A, Pels H, Rogowski S, et al. Long-term survival with favorable cognitive outcome after chemotherapy in primary central nervous system lymphoma. Ann Neurol. 2010;67:182-9.

36. Pels H, Juergens A, Glasmacher A, et al. Early relapses in primary CNS lymphoma after response to polychemotherapy without intraventricular treatment: results of a phase II study. J Neurooncol. 2009;91:299-305.

37. Khan RB, Shi W, Thaler HT, et al. Is intrathecal methotrexate necessary in the treatment of primary CNS lymphoma? J Neurooncol. 2002;58:175-8.

38. Sierra Del Rio M, Ricard D, Houillier C, et al. Prophylactic intrathecal chemotherapy in primary CNS lymphoma. J Neurooncol. 2012;106:143-6.

In this retrospective study, the authors investigated the role of intrathecal chemotherapy in addition to HD-MTX based regimen and found no benefit.

39. Angelov L, Doolittle ND, Kraemer DF, et al. Bloodbrain barrier disruption and intra-arterial methotrexate-based therapy for newly diagnosed primary CNS lymphoma: a multi-institutional experience. J Clin Oncol. 2009;27:3503-9.

40. Ruhstaller TW, Amsler U, Cerny T. Rituximab: active treatment of central nervous system involvement by non-Hodgkin's lymphoma? Ann Oncol. 2000;11:374-5.

41. Abrey LE, Moskowitz CH, Mason WP, et al. Intensive methotrexate and cytarabine followed by high-dose chemotherapy with autologous stem-cell rescue in patients with newly diagnosed primary CNS lymphoma: an intent-to-treat analysis. J Clin Oncol. 2003;21:4151-6.

42. Colombat P, Lemevel A, Bertrand P, et al. High-dose chemotherapy with autologous stem cell transplantation as first-line therapy for primary CNS lymphoma in patients younger than 60 years: a multicenter phase II study of the GOELAMS group. Bone Marrow Transplant. 2006;38:417-20.

43. Montemurro M, Kiefer T, Schuler F, et al. Primary central nervous system lymphoma treated with high-dose methotrexate, high-dose busulfan/thiotepa, autologous stem-cell transplantation and response-adapted whole-brain radiotherapy: results of the multicenter Ostdeutsche Studiengruppe Hamato-Onkologie OSHO-53 phase II study. Ann Oncol. 2007; 18:665-71.

44. Kiefer T, Hirt C, Spath C, et al. Long-term follow-up of high-dose chemotherapy with autologous stemcell transplantation and response-adapted wholebrain radiotherapy for newly diagnosed primary CNS lymphoma: results of the multicenter Ostdeutsche Studiengruppe Hamatologie und Onkologie OSHO53 phase II study. Ann Oncol. 2012;23:1809-12.
In this study, the authors reported the long-term follow-up results of patients treated with HDCT + ASCT followed by WBRT, with a report on overall survival as well as quality of life and neurotoxicity.

45. Illerhaus G, Marks R, Ihorst G, et al. High-dose chemotherapy with autologous stem-cell transplantation and hyperfractionated radiotherapy as first-line treatment of primary CNS lymphoma. J Clin Oncol. 2006;24:3865-70.

46. Illerhaus G, Muller F, Feuerhake F, et al. High-dose chemotherapy and autologous stem-cell transplantation without consolidating radiotherapy as firstline treatment for primary lymphoma of the central nervous system. Haematologica. 2008;93:147-8.

47. Kasenda B, Schorb E, Fritsch K, et al. Prognosis after high-dose chemotherapy followed by autologous stem-cell transplantation as first-line treatment in primary CNS lymphoma-a long-term follow-up study. Ann Oncol. 2012;23:2670-5.

48. Yoon DH, Lee DH, Choi DR, et al. Feasibility of BU, CY and etoposide (BUCYE), and auto-SCT in patients with newly diagnosed primary CNS lymphoma: a single-center experience. Bone Marrow Transplant. 2011;46:105-9.

49.• Illerhaus G, Fritsch K, Egerer G, et al.: Sequential High Dose Immuno-Chemotherapy Followed by Autologous Peripheral Blood Stem Cell Transplantation for Patients with Untreated Primary Central Nervous System Lymphoma - a Multicentre Study by the Collaborative PCNSL Study Group Freiburg. Blood 2012, 120. Presented at the American Society of Hematology annual meeting, Atlanta, 2012.

This study demonstrated that HDCT followed by ASCT is highly effective in young patients with newly diagnosed PCNSL.

50. Schorb E, Kasenda B, Atta J, et al. Prognosis of patients with primary central nervous system lymphoma after high-dose chemotherapy followed by autologous stem cell transplantation. Haematologica. 2013;98:765-70.

This study provided 5-year survival data on newly diagnosed PCNSL patients treated with HDCT and ASCT.

51. Norden AD, Drappatz J, Wen PY, Claus EB. Survival among patients with primary central nervous system lymphoma, 1973-2004. J Neurooncol. 2011;101:487-93.

52. Abrey LE, Yahalom J, DeAngelis LM. Treatment for primary CNS lymphoma: the next step. J Clin Oncol. 2000;18:3144-50.

53. Jahnke K, Korfel A, Martus P, et al. High-dose methotrexate toxicity in elderly patients with primary central nervous system lymphoma. Ann Oncol. 2005;16:445-9.

54. Zhu JJ, Gerstner ER, Engler DA, et al. High-dose methotrexate for elderly patients with primary CNS lymphoma. Neuro Oncol. 2009;11:211-5.

55. Ney DE, Reiner AS, Panageas KS, et al. Characteristics and outcomes of elderly patients with primary cen- 
tral nervous system lymphoma: the Memorial SloanKettering Cancer Center experience. Cancer. 2010;116:4605-12.

56. Welch MR, Omuro A, Deangelis LM. Outcomes of the oldest patients with primary CNS lymphoma treated at Memorial Sloan-Kettering Cancer Center. Neuro Oncol. 2012;14:1304-11.

57. Omuro AM, Taillandier L, Chinot $\mathrm{O}$, et al. Temozolomide and methotrexate for primary central nervous system lymphoma in the elderly. J

Neurooncol. 2007;85:207-11.

58. Hoang-Xuan K, Taillandier L, Chinot O, et al. Chemotherapy alone as initial treatment for primary CNS lymphoma in patients older than 60 years: a multicenter phase II study (26952) of the European Organization for Research and Treatment of Cancer Brain Tumor Group. J Clin Oncol. 2003;21:2726-31.

59. Illerhaus G, Marks R, Muller F, et al. High-dose methotrexate combined with procarbazine and CCNU for primary CNS lymphoma in the elderly: results of a prospective pilot and phase II study. Ann Oncol. 2009;20:319-25.

60. Fritsch K, Kasenda B, Hader C, et al. Immunochemotherapy with rituximab, methotrexate, procarbazine, and lomustine for primary CNS lymphoma (PCNSL) in the elderly. Ann Oncol. 2011;22:2080-5.

61.• Omuro A, Chinot O, Taillandier L, et al.: Multicenter randomized phase II trial of methotrexate (MTX) and temozolomide (TMZ) versus MTX, procarbazine, vincristine, and cytarabine for primary CNS lymphoma (PCNSL) in the elderly: An Anocef and Goelams Intergroup study. J Clin Oncol supplement, 2013. Presented at the American Society of Clinical Oncology annual meeting, Chicago 2013.

This was the first randomized trial for PCNSL in the elderly, which showed a trend toward better outcomes for HD-MTX, procarbazine, vincristine and cytarabine combination, although this was not statistically significant.

62. Plotkin SR, Betensky RA, Hochberg FH, et al. Treatment of relapsed central nervous system lymphoma with high-dose methotrexate. Clin Cancer Res. 2004; 10:5643-6.

63. Raizer JJ, Rademaker A, Evens AM, et al. Pemetrexed in the treatment of relapsed/refractory primary central nervous system lymphoma. Cancer. 2012;118:3743-8.

This study showed the benefit of pemetrexed in relapsed PCNSL.

64. Makino K, Nakamura H, Hide T, Kuratsu J. Salvage treatment with temozolomide in refractory or relapsed primary central nervous system lymphoma and assessment of the MGMT status. J Neurooncol. 2012;106:155-60.

65. Reni M, Zaja F, Mason W, et al. Temozolomide as salvage treatment in primary brain lymphomas. Br J Cancer. 2007;96:864-7.
66. Batchelor TT, Grossman SA, Mikkelsen T, et al. Rituximab monotherapy for patients with recurrent primary CNS lymphoma. Neurology. 2011;76:929-30.

This study demonstrated that single agent rituximab was active in patients with relapsed PCNSL.

67. Enting RH, Demopoulos A, DeAngelis LM, Abrey LE. Salvage therapy for primary CNS lymphoma with a combination of rituximab and temozolomide. Neurology. 2004;63:901-3.

68. Nayak L, Abrey LE, Drappatz J, et al. Multicenter phase II study of rituximab and temozolomide in recurrent primary central nervous system lymphoma. Leuk Lymphoma. 2013;54:58-61.

69. Wong ET, Tishler R, Barron L, Wu JK. Immunochemotherapy with rituximab and temozolomide for central nervous system lymphomas. Cancer. 2004;101:139-45.

70. Fischer L, Thiel E, Klasen HA, et al. Prospective trial on topotecan salvage therapy in primary CNS lymphoma. Ann Oncol. 2006;17:1141-5.

71. Voloschin AD, Betensky R, Wen PY, et al. Topotecan as salvage therapy for relapsed or refractory primary central nervous system lymphoma. J Neurooncol. 2008;86:211-5.

72. Arellano-Rodrigo E, Lopez-Guillermo A, Bessell EM, et al. Salvage treatment with etoposide (VP-16), ifosfamide and cytarabine (Ara-C) for patients with recurrent primary central nervous system lymphoma. Eur J Haematol. 2003;70:219-24.

73. Herrlinger U, Brugger W, Bamberg M, et al. PCV salvage chemotherapy for recurrent primary CNS lymphoma. Neurology. 2000;54:1707-8.

74. Rubenstein JL, Treseler PA, Stewart PJ. Regression of refractory intraocular large B-cell lymphoma with lenalidomide monotherapy. J Clin Oncol. 2011;29:e595-597.

75. Rubenstein JL, Fridlyand J, Abrey L, et al. Phase I study of intraventricular administration of rituximab in patients with recurrent CNS and intraocular lymphoma. J Clin Oncol. 2007;25:1350-6.

76. Rubenstein JL, Li J, Chen L, et al. Multicenter phase 1 trial of intraventricular immunochemotherapy in recurrent CNS lymphoma. Blood. 2013;121:745-51.

77. Soussain C, Hoang-Xuan K, Taillandier L, et al. Intensive chemotherapy followed by hematopoietic stem-cell rescue for refractory and recurrent primary CNS and intraocular lymphoma: Societe Francaise de Greffe de Moelle Osseuse-Therapie Cellulaire. J Clin Oncol. 2008;26:2512-8.

78. Kasenda B, Schorb E, Fritsch K, et al. Primary CNS lymphoma-radiation-free salvage therapy by second autologous stem cell transplantation. Biol Blood Marrow Transplant. 2011;17:281-3.

79. Harker-Murray PD, Thomas AJ, Wagner JE, et al. Allogeneic hematopoietic cell transplantation in children with relapsed acute lymphoblastic leukemia isolated to the central nervous system. Biol Blood Marrow Transplant. 2008;14:685-92. 
80. Fukushima T, Taguchi J, Moriuchi Y, et al. Allogeneic hematopoietic stem cell transplantation for ATL with central nervous system involvement: the Nagasaki transplant group experience. Int J Hematol. 2011;94:390-4.

81. Busemann C, Gudzuhn A, Hirt C, et al. Treatment of splenic marginal zone lymphoma of the CNS with high-dose therapy and allogeneic stem cell transplantation. Exp Hematol Oncol. 2012;1:32.

82. Shimura H, Imai $Y$, Ishiyama $M$, et al. Long-term remission after nonmyeloablative allogeneic bone marrow transplantation in a relapsed Hodgkin lymphoma patient with CNS involvement. Rinsho Ketsueki. 2012;53:1991-6.
83. Varadi G, Or R, Kapelushnik J, et al. Graft-versuslymphoma effect after allogeneic peripheral blood stem cell transplantation for primary central nervous system lymphoma. Leuk Lymphoma. 1999;34:18590 .

84. Nguyen PL, Chakravarti A, Finkelstein DM, et al. Results of whole-brain radiation as salvage of methotrexate failure for immunocompetent patients with primary CNS lymphoma. J Clin Oncol.

2005;23:1507-13.

85. Hottinger AF, DeAngelis LM, Yahalom J, Abrey LE. Salvage whole brain radiotherapy for recurrent or refractory primary CNS lymphoma. Neurology. 2007;69:1178-82. 